\title{
Coordination contracts of dual-channel with cooperation advertising in closed-loop supply chains
}

\author{
JiaPing Xie ${ }^{a}$, Ling Liang ${ }^{b, *}$, LuHao Liu $^{a}$, Petros Ieromonachou ${ }^{c}$ \\ a School of International Business Administration, Shanghai University of Finance and Economics, Shanghai, PR China \\ ${ }^{\mathrm{b}}$ Tourism and Event Management School, Shanghai University of International Business and Economics, Shanghai, PR China \\ ${ }^{\text {c }}$ Faculty of Business, University of Greenwich, London SE10 9LS, UK
}

\section{A R T I C L E I N F O}

Article history:

Received 30 October 2015

Received in revised form

24 July 2016

Accepted 30 July 2016

\section{Keywords:}

Closed-loop supply chains

Contract coordination

Channel conflict

Revenue sharing

Online to offline

\begin{abstract}
A B S T R A C T
On the background of an online/offline dual channel, this paper studies contract coordination of centralized and decentralized dual-channel closed-loop supply chains. With the feature of recycle rate fluctuation, we develop a revenue-sharing mechanism by taking the relationship between the recycle rate and the recycle revenue sharing ratio into consideration. After comparing of centralized decision and the manufacturing led decentralized decision, the optimal online/offline price, wholesale price and advertising investment are derived. The influence of revenue sharing ratio in forward and reverse channels on the online/offline prices and wholesale prices is discussed. The numeric example is used for observing the relationship between variables, and between the optimal profit and variables through analysis of changing parameter valuations.
\end{abstract}

(c) 2016 Elsevier B.V. All rights reserved.

\section{Introduction}

In the era of E-commerce, many enterprises choose to develop an online channel for direct sales with the traditional retail channel being maintained to establish an online/offline dualchannel distribution system. In the dual-channel of supply chains (SCs), manufacturers not only work as the upstream suppliers, but also as the peer competitors on the same level. On one hand, manufacturers control the scale of traditional retail channels by establishing online routes to restrict the retailers' bargaining power. On the other hand, traditional retail channels continue to play an irreplaceable role: the brand effect is cultivated by providing offline service support, customer experience and product maintenance, and the customers' post-market service demands are therefore created and satisfied.

By comparing the prices and profits under three modes-online, offline and mixed channels-and discussing the effect of cost structure and elasticity of demand in pricing, Park and Keh (2003) believe that manufacturers adopting a mixed channel strategy can reduce retail price, boost demand and increase the total profit of both the manufacturer and the SC. These days, manufacturers constantly devote themselves to improving the shopping experience and aftermarket service of physical retail stores, with

\footnotetext{
* Corresponding author at: Tourism and Event Management School, Shanghai University of International Business and Economics, Shanghai, PR China.

E-mail addresses: jiaping@mail.shufe.edu.cn (J. Xie),

liang-ling@foxmail.com (L. Liang), IP07@gre.ac.uk (P. Ieromonachou).
}

focusing on service competition strategy rather than price competition strategy. For the purpose of reducing the negative effects of the online channel for direct sales on the offline retail channel, some manufacturers seek cooperation relating to market service support, such as part exchange and product repair, so that retailers will be able to gain service benefits from E-channels. Dan et al. (2012) study the dual-channel of a conventional SC where retailer provides service and decides the pricing and service strategy. They conclude that retailers should increase the retail price as a result of improved service and the manufacturer's pricing strategy depends on consumer loyalty.

On the other hand, an enterprise's environmental responsibility has become an inescapable practical problem. Remanufacturing saves costs and the recycling of used products contributes to increased profits, so manufacturing enterprises tend to recycle used products in a more active way and implement closed-loop supply chains (CLSC). Savaskan et al. (2004) discuss three different recycling scenarios where manufacturers, retailers and third parties playing a leading role respectively. By comparing the impact of wholesale price, retail price and recycle rate on the total profit of CLSC under these three scenarios, the study shows that manufactures' profit is maximized when recycling led by the retailer. Jing and Bell (2012) discuss whether the recycling channel and recycling price would affect retailers' pricing and order decisions, with return rate, return cost and consumers' return preferences as parameters in the study. They conclude that the recycling mechanism could improve profits for retailers.

For advertising investment decisions, Yue et al. (2006) and Xie 


\begin{tabular}{|c|c|c|}
\hline \multicolumn{2}{|c|}{ Nomenclature } & \multirow[t]{2}{*}{$1-\alpha$} \\
\hline$Q$ & $\begin{array}{l}\text { Total market demand when the dual-channel product } \\
\text { price and advertising investment levels are zero }\end{array}$ & \\
\hline$A$ & Recycling channel input & \\
\hline$c$ & Unit manufacturing cost & $P_{t}$ \\
\hline$s$ & Unit cost saving by remanufacturing & $P_{e}$ \\
\hline$\beta$ & Intrinsic price elastic coefficient & $w$ \\
\hline$\delta$ & Cross-price elastic coefficient, $0<\delta<\beta$ & $b$ \\
\hline$k$ & $\begin{array}{l}\text { Advertising effect, the influence factor of advertising } \\
\text { investment on total market demand, } k>0\end{array}$ & $\Phi_{1}$ \\
\hline$i$ & Recycle rate for used products & \\
\hline$\rho$ & $\begin{array}{l}\text { Consumers' preference for the offline channel, } \\
0 \leq \rho \leq 1\end{array}$ & $\Phi_{2}$ \\
\hline $1-\rho$ & Consumers' preference for the online channel & \\
\hline$\alpha$ & $\begin{array}{l}\text { The advertising expense proportion assumed by the } \\
\text { manufacturer, } 0 \leq \alpha \leq 1\end{array}$ & \\
\hline
\end{tabular}

The advertising expense proportion assumed by the retailer

Variables

1 Offline price

Online price, $P_{t}>P_{e}$

Wholesale price

Total advertising investment of the dual-channel SC

Revenue sharing ratio in forward channel-RSR-FC, the ratio of manufacturer shares sales revenue from an offline channel of the retailer, $0 \leq \Phi_{1} \leq 1$

Revenue sharing ratio in reverse channel-RSR-RC, the ratio of retailer shares remanufacturing cost savings from recycling, $0 \leq \Phi_{2} \leq 1$ and Wei (2009) analyze the optimal price and advertising decisions in a conventional forward SC of the offline channel when market demand is affected by price and advertising investment; while Szmerekovsky and Zhang (2009) look for the optimal decision when both the manufacturer and retailer invested in advertising. Pietro (2014) claims green advertising investment helps establish commercial goodwill for both manufacturer and retailer. So it can stimulate investment for green advertising if reverse revenue sharing contract is adopted in reverse supply-chain of closed-loop supply chain. Yi and Xiao (2012) construct a CLSC game theory model of certain demands under the influence of advertising, and discuss optimal pricing, advertising investment and recycle rate decisions as well as the coordination method. However, most scholars discuss the optimal pricing decision and cooperation advertising strategies in a dual-channel forward SC based on the assumption that demand is only affected by advertising; the influence of the competitive channel price on the channel price itself is not covered in the demand function. In fact, advertising investment will not increase product demand, but change the distribution of product demand in different channels.

"Double marginalization" decided by channel members exist in dual-channel closed-loop networks. After comparison and analysis of revenue-sharing contracts, buyback contracts and wholesale price contracts, Cachon and Lariviere (2005) conclude that revenue-sharing contracts can coordinate the SC channel and determine the retail price and the retailers' pricing, which is better than the coordination of buyback and discount contracts in a single case; besides, in revenue-sharing contracts, SC profits can be divided arbitrarily instead of depending on the retailers' order quantity and price option. Yan and Pei (2011) show that although retailers and manufacturers could share the information about consumer demand, only manufacturers could benefit from the information sharing, while the retailer unaffected. Altug (2016) discusses the impaction of revenue sharing contract in contract design from the perspective of cost. He regards cost as added value for contractor. Different types of revenue sharing brings different cost in the process of executing contract. Xu et al. (2014) establish a dual-channel supply chain coordinating contract, which consists of a two-way revenue sharing contract. Manufacturer gets a fraction of the revenue generated by retailer's channel in the traditional revenue sharing contract, while retailer gets a fraction of the revenue generated by manufacturer's direct channel in the reverse revenue sharing contract. However they do not consider recycling and remanufacturing, as well as sharing for remanufacturing cost savings. Yi and Yuan (2012) research on the influence of channel conflict on CLSC coordination in mixed sales channels. Therefore, for node enterprises in dual-channel closed-loop distribution networks, eliminating channel conflict and double marginalization has been a new eminent task.

Some manufacturers have already adopted a differential price strategy and service strategy in order to relieve the competition conflict between manufacturers and retailers. The mode has relieved channel conflict to a certain degree, but will it resolve dual marginalization altogether? How much do centralized versus decentralized decisions differentiate? And how are the profits of all members of the SC reallocated and reach a better recycle rate by determining a reasonable revenue sharing ratio in the CLSC? These are the questions studied and answered in this paper.

The remainder of this paper is organized as follows. Section 2 introduces the problem description and model. In Section 3, channel conflict coordination model of cooperative advertising in centralized CLSC is discussed, followed by the numerical analysis. Section 4 presents discussion of channel conflict coordination model of cooperation advertising in decentralized CLSC, as well as comparing with the performance in centralized CLSC. Section 5 summarizes the findings.

\section{Problem description and model}

\subsection{Problem description}

Fig. 1 shows a dual-channel CLSC consisting of single manufacturer/single retailer. The sales channel of this kind is about the simultaneous online and offline sales of certain products produced by the manufacturer at unit cost $c$. The manufacturer wholesales the product to the retailer in the wholesale price $\mathrm{w}$ through the offline channel, the retailer sells the product to consumers at the offline price $P_{t}$ and the manufacturer sells the product to consumers at the direct sale price $P_{e}$ through the online channel. Total

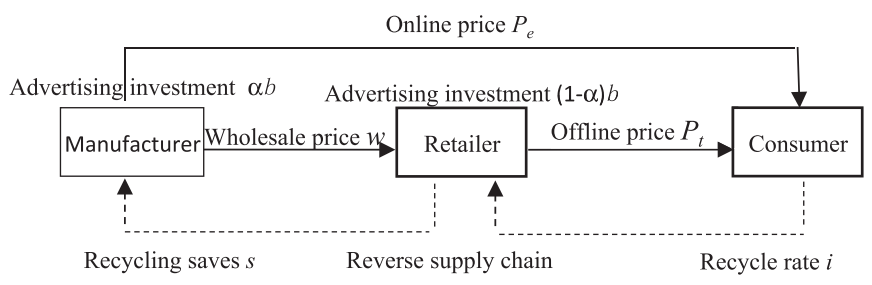

Fig. 1. Revenue-sharing decision model of cooperation advertising in a dualchannel CLSC. 
advertising investment of the dual-channel SC is $b$. Supposing the advertising expense proportion assumed by the retailer is $1-\alpha$, then the proportion assumed by the manufacturer is $\alpha$.

Manufacturers can recycle a certain percentage of used products that are at the end of their service life, and the recycle rate is $i$. The remanufacturing cost is lower than the manufacturing cost of new products, $s$ is the cost saved for the manufacturer by recycling 1 unit of used products. To encourage the retailers to assist in recycling, the manufacturer will share its remanufacturing cost savings with the retailer. Wei and Choi (2012) believe that SC profits can be optimized through the wholesale price discount and revenue-sharing contract, and, what is more, the wholesale price decreases as the revenue-sharing proportion increases. Adopting the model from Cachon and Lariviere (2005), that revenue-sharing contract can coordinate the forward SC, we consider the competition relationship between manufacturer and retailer in dualchannel SC during a sale process. A dual revenue-sharing contract dominated by the manufacturer is hereby designed: the retailer shares $\Phi_{2}$ proportion of remanufacturing cost savings from recycling, i.e. revenue-sharing ratio in reverse channel (RSR-RC); the manufacturer enjoys $\Phi_{1}$ proportion of sales revenue from an offline channel of the retailer. i.e. revenue sharing ratio in forward channel (regular channel) (RSR-FC). Both the channel revenuesharing coefficient $\Phi_{1}$ and $\Phi_{2}$ are larger than 0 and smaller than 1 .

\subsection{Mathematical model}

Niu et al. (2012) recognize that demand for both an online channel for direct sales and a traditional retail channel was the same, and in accordance with the linear demand function in general; however, E-sale and a traditional retail channel are distinguished by the price sensitivity, and the studied dual-channel pricing and ordering decision-making are different in terms of channel price. In the study of competitive pricing determined by total market demand, Gallego and Hu (2014) also believe that the demand function in the price game satisfied the linear relationship. On the other hand, advertising realizes product publicity and increases consumers' awareness of the product, so that consumers' total market demand increases. Therefore, in this paper, we assumed that demands are affected by dual-channel price and advertising investment at the same time. In the demand function, the effect of advertising investment on demand $k \sqrt{b}$ is a convex function with respect to $b$, which is consistent with the effect of advertising on demand in the research conducted by Horsky and Simon (1983). Hence, the definition of online/offline channel demand is as shown in the Eqs. (1) and (2):

The demand of offline channel is $D_{t}=\rho(Q+k \sqrt{b})-\beta P_{t}+\delta P_{e}$

The demand of online channel is $D_{e}=(1-\rho)(Q+k \sqrt{b})-\beta P_{e}+\delta P_{t}$

where subscript $t$ stands for offline channel, subscript $e$ for online channel and $Q$ for total market demand when the dual-channel product price and advertising investment levels are zero. $\rho$ and $1-\rho$ refer to the consumers' preference for the offline channel and online channel respectively, and $0 \leq \rho \leq 1$.

Hua et al. (2010) and Peng et al. (2015) assume that the intrinsic price elastic coefficient and cross-price elastic coefficient of channels are symmetric, which means different channels have the same intrinsic price elastic coefficient and cross-price elastic coefficient. This paper quotes this conclusion for the convenience of analysis. In the equations, $\beta$ stands for the intrinsic price elastic coefficient, $\delta$ for cross-price elastic coefficient, and $0<\delta<\beta$ means demand is affected by the intrinsic price in a more significant manner than the price of another channel. $k$ is the influence factor of advertising investment on total market demand, i.e. advertising effect, and $k>0$.

The quantity of used products recycled by retailers is relevant to the quantity of recycling sites. The more recycling sites, the more recycled products. So the recycling quantity is positively correlated to recycling channel input of retailers'. However, due to diminishing marginal effect of channel input; i.e. the recycling rate $i$ is defined as a concave function of recycling channel input. Thus, $A$ is introduced in this paper as recycling channel input. By referring to Savaskan et al. (2004), $i=\gamma \sqrt{A}$, where $\gamma$ is input coefficient. In addition, recycling channel input $A$ increases when $\Phi_{2}$ increases. Therefore, the recycling rate $i$ is a variable and is the function of $\Phi_{2}$. In previous literatures (Xing et al., 2007), the recycling channel input is an exponential function of $\Phi_{2}$, i.e. $A=\theta e^{\Phi_{2}}(\theta>0)$, and $i=\gamma \sqrt{\theta e^{\Phi_{2}}}=\gamma \sqrt{\theta} e^{\frac{1}{2} \Phi_{2}}$, recorded as $\mu=\gamma \sqrt{\theta}$, and $i=\mu e^{\frac{1}{2} \Phi_{2}}, \mu>0$.

As the cost saving of recycling is high and shared by the retailer, the more active the retailer becomes in recycling, and, as a result, the recycling rate of used products increases. Therefore, the recycling rate is correlated with RSR-RC, and the correlation is used to study the pricing optimization in centralized and decentralized decision-making.

Assume the retailer ordering quantity is equal to the sum of sales through both offline and online channels. And the sales through two channels is equal to the demand of online and offline channels respectively. The profit function of the manufacturer, retailer and SC-without considering storage and inventory costs -is as below:

The profit function of the manufacturer:

$\pi_{M}=w D_{t}+P_{e} D_{e}+\Phi_{1} P_{t} D_{t}+\left(\left(1-\Phi_{2}\right) S \mu e^{\frac{1}{2} \Phi_{2}}-c\right)\left(D_{t}+D_{e}\right)-\alpha b$

The profit function of the retailer:

$\pi_{R}=\left(1-\Phi_{1}\right) P_{t} D_{t}-w D_{t}+\Phi_{2} S \mu e^{\frac{1}{2} \Phi_{2}}\left(D_{t}+D_{e}\right)-(1-\alpha) b$

where the manufacturer's revenue consists of the wholesale revenue to retailers $w D_{t}$, the online sales revenue $P_{e} D_{e}$, the fraction of remanufacturing cost saving the manufacturer keeps $\left(1-\Phi_{2}\right) S \mu e^{\frac{1}{2} \Phi_{2}}\left(D_{t}+D_{e}\right)$, and the share from the retailer's offline sales revenue $\Phi_{1} P_{t} D_{t}$; It's expenditure consists of the manufacturing cost $c\left(D_{t}+D_{e}\right)$ and the advertising investment $\alpha b$;

Also, the retailer's revenue consists of the fraction of offline sales revenue the retailer keeps $\left(1-\Phi_{1}\right) P_{t} D_{t}$ and the share from remanufacturing cost saving $\Phi_{2} S \mu e^{\frac{1}{2}} \Phi_{2}\left(D_{t}+D_{e}\right)$; It's expenditure consists of the payment for products $w D_{t}$ and advertising investment $(1-\alpha) b$.

The profit function of the SC:

$\pi=P_{e} D_{e}+P_{t} D_{t}-c\left(D_{t}+D_{e}\right)+S \mu e^{\frac{1}{2} \Phi_{2}}\left(D_{t}+D_{e}\right)-b$

where the whole revenue of SC consists of online/offline sales revenue $P_{e} D_{e}+P_{t} D_{t}$ and the remanufacturing cost saving $s \mu e^{\frac{1}{2} \Phi_{2}}\left(D_{t}+D_{e}\right)$; The SC expenditure consists of manufacturing cost $c\left(D_{t}+D_{e}\right)$ and the advertising investment $b$. RSR-RC, $\Phi_{2}$, could still affect the SC profits because the recycling rate $i$ is not fixed and in correlation with revenue sharing of retailers' in reverse SC, which is different from the viewpoints in previous research (QuariguasiFrota-Neto and Bloemhof, 2011; Debo et al., 2006) with premise for fixed recycling rate. 


\section{Channel conflict coordination model of cooperative adver- tising in centralized CLSC}

\subsection{Centralized decision model and solution of the model}

By substituting Eqs. (1) and (2) into (5), the profit function of the SC under centralized decision is:

$$
\begin{aligned}
\pi= & \left(P_{t}-c\right)\left(\rho(Q+k \sqrt{b})+\delta P_{e}-\beta P_{t}\right)+\left(P_{e}-c\right)\left((1-\rho)(Q+k \sqrt{b})-\beta P_{e}+\delta P_{t}\right) \\
& +S \mu e^{\frac{1}{2} \Phi_{2}}\left(Q+k \sqrt{b}+(\delta-\beta)\left(P_{t}+P_{e}\right)\right)-b
\end{aligned}
$$

As the cost-saving benefiting from recycling and remanufacturing is affected by the RSR-RC, it can be said that under the centralized decision model, the total SC profit is influenced by the RSR-RC. This conclusion is different from conventional SC (Krishnan and Winter, 2011; Wang et al., 2004) the revenuesharing contract of which is not impacted by allocation ratio coefficient in the overall SC profit function. In Eq. (6), the first item represents the product's selling profit in the offline channel, the second item represents the product's selling profit in the online channel, the third item represents the product yield of the recycling channel, and the fourth item represents the advertising investment of the SC.

The optimal online price $P_{e}$ and offline price $P_{t}$ of dual-channel supply chain can be obtained with first-order optimality conditions.

$$
\begin{aligned}
& \text { Suppose } \frac{\partial \pi}{\partial P_{t}}=0, \frac{\partial \pi}{\partial P_{e}}=0, \frac{\partial \pi}{\partial \sqrt{b}}=0 \text {, so } \\
& \frac{\partial \pi}{\partial P_{t}}=-2 \beta P_{t}+2 \delta P_{e}+\rho Q+k_{t} \sqrt{b}+\beta c-\delta c-s \mu e^{\frac{1}{2} \Phi_{2}}(\beta-\delta)=0 \\
& \frac{\partial \pi}{\partial P_{e}}=-2 \beta P_{e}+2 \delta P_{t}+(1-\rho) Q+k_{e} \sqrt{b}+\beta c-\delta c-s \mu e^{\frac{1}{2} \Phi_{2}}(\beta-\delta)=0 \\
& \frac{\partial \pi}{\partial \sqrt{b}}=k\left(\left(P_{t}+(1-\rho) P_{e}-c+s \mu e^{\frac{1}{2} \Phi_{2}}\right)-2 \sqrt{b}=0\right.
\end{aligned}
$$

By solving the equations we can obtain expressions of the unique optimal online price $P_{e}$ and offline price $P_{t}$ aw well as critical advertising investment value $\sqrt{b_{0}^{*}}$ :

$P_{e}^{c^{*}}(\sqrt{b})=\frac{N(Q+k \sqrt{b})+G}{2}$

$P_{t}^{c^{*}}(\sqrt{b})=\frac{M(Q+k \sqrt{b})+G}{2}$

$\sqrt{b_{o}^{*}}=-\frac{k\left(4 Q A+s \mu e^{\frac{1}{2} \Phi_{2}}-c\right)}{4\left(k^{2} A-1\right)}$

where $M=\frac{\beta \rho+\delta(1-\rho)}{\beta^{2}-\delta^{2}}, N=\frac{\delta \rho+\beta(1-\rho)}{\beta^{2}-\delta^{2}}, G=c-s \mu e^{\frac{1}{2} \Phi_{2}}, A=\frac{\beta-2 \rho(\beta-\delta)(1-\rho)}{4\left(\beta^{2}-\delta^{2}\right)}$

Theorem 1. $\pi\left(P_{t}, P_{e}, \sqrt{b}, \Phi_{2}\right)$, the total profit of a centralized CLSC is a strictly concave function with respect to $\sqrt{b}$, and also the strictly combined concave function with respect to $P_{t}$ and $P_{e}$, but is not a combined concave function with respect to $P_{t}, P_{e}, \sqrt{b}, \Phi_{2}$ [Appendix A].

Theorem 2. For the given advertising investment $\sqrt{b}$ and revenue sharing ratio $\Phi_{2}$, the centralized CLSC has a unique optimal online price $P_{e}^{c^{*}}$ and offline price $P_{t}^{c^{*}}$.

Theorem 3. Advertising investment has a unique critical value $\sqrt{b_{0}^{*}}$, and the optimal SC profit exists. The optimal profit of the SC is:

$$
\begin{aligned}
\pi^{*}\left(\sqrt{b}, \Phi_{2}\right)= & \left(k^{2} A-1\right) \sqrt{b}^{2}+\left(2 Q A+\frac{s \mu e^{\frac{1}{2} \Phi_{2}}-c}{2}\right) \\
& \times k \sqrt{b}+A Q^{2}+\frac{\left(s \mu e^{\frac{1}{2} \Phi_{2}}-c\right) Q}{2}+\frac{\beta-\delta}{2}\left(s \mu e^{\frac{1}{2} \Phi_{2}}-c\right)^{2}
\end{aligned}
$$

3.2. The property analysis to the solutions of the centralized decision model

In this section we discuss property for optimal online/offline price, optimal advertising investment, and optimal profit of the SC. It can be shown that all above optimal solutions are affected by RSR-RC or consumers' preferences.

\subsubsection{The property analysis to optimal online/offline price}

Take the derivatives of the expressions of $P_{e}^{c^{*}}$ and $P_{t}^{c^{*}}$ with respect to $\sqrt{b}$, and it can be solved that:

$$
\begin{aligned}
& \frac{d P_{e}^{c^{*}}(\sqrt{b})}{d \sqrt{b}}=\frac{k}{2} N>0 \\
& \frac{d P_{t}^{c^{*}}(\sqrt{b})}{d \sqrt{b}}=\frac{k}{2} M>0 \\
& \frac{d P_{t}^{c^{*}}(\sqrt{b})}{d \sqrt{b}}-\frac{d P_{e}^{c^{*}}(\sqrt{b})}{d \sqrt{b}}=\frac{k(2 \rho-1)}{\beta+\delta}
\end{aligned}
$$

Property 1. The optimal online/offline price increases as advertising investment increases, and increased amount relates to consumers' preference for online or offline channels.

The price of the channel consumers preferred changes more significantly with respect to the advertising investment of the channel, compared to the changes in the other channel, i.e. if $\frac{d P_{e}^{C^{*}}(\sqrt{b})}{d \sqrt{b}}>0, \frac{d P_{t}^{c^{*}}(\sqrt{b})}{d \sqrt{b}}>0$, when $0<\rho<\frac{1}{2}, \frac{d P_{t}^{C^{*}}(\sqrt{b})}{d \sqrt{b}}<\frac{d P_{e}^{c^{*}}(\sqrt{b})}{d \sqrt{b}}$; when $\rho \geq \frac{1}{2}$, $\frac{d P_{t}^{*}(\sqrt{b})}{d \sqrt{b}} \geq \frac{d P_{e}^{c^{*}}(\sqrt{b})}{d \sqrt{b}}$, which indicates that the optimal online or offline price increases as advertising investment increases. Increase in advertising investment will boost the demand of each channel and lead to the price increase in the online and offline channels. Under the condition that extent of advertising affect demand is same between different channels, if consumers prefer online channel, increased demand of online channel will be greater than that of offline channel. Therefore, optimal online price increases faster than that of offline price. Vice versa.

Property 2. The optimal price changes according to consumers preferences. Firstly, the optimal price of the consumers' preferred channel is higher than that of the other channel. Secondly, the optimal offline channel price increases when consumers' preference for the offline channel increases, while the online price increases as consumers' preference for the offline channel decrease, and the range of variation is the same but in opposite direction.

(1) When $0<\rho<\frac{1}{2}, \quad P_{t}^{c^{*}}(\sqrt{b})<P_{e}^{c^{*}}(\sqrt{b})$; when $\rho \geq \frac{1}{2}$, then $P_{t}^{c^{*}}(\sqrt{b}) \geq P_{e}^{c^{*}}(\sqrt{b})$. It can be concluded that if consumers' preference for the offline channel is smaller than 0.5 , which means consumers prefer to buy products through the online channel, the optimal online price will be higher than the optimal offline price no matter how much is invested in advertising by the SC. Otherwise, the optimal offline price will be 
higher than the optimal online price.

(2) Derivative of the optimal online price and offline price with respect to the channel preference coefficient:

$\frac{d \mathrm{P}_{t}^{c}(\sqrt{b})}{d \rho}=-\frac{d \mathrm{P}_{e}^{c}(\sqrt{b})}{d \rho}=\frac{1}{2(\beta+\delta)}(Q+k \sqrt{b})>0$

The reason is that the demand for the offline channel rises when consumers' preference for the offline channel increases. As a result, the product price of the offline channel rises. In the same way, demand for the online channel decreases and the product price of the online channel drops. The intrinsic price elasticity and cross-price elasticity of different channels are equal. Therefore, the rate of change of optimal prices is equal, but the direction of change is opposite.

Property 3. Both the optimal online and offline prices are monotonically decreasing functions with respect to the RSR-RC; the larger the RSR-RC, the lower the optimal online/offline price.

$\frac{d \mathrm{P}_{e}^{c}(\sqrt{b})}{d \Phi_{2}}=\frac{d \mathrm{P}_{t}^{c}(\sqrt{b})}{d \Phi_{2}}=-\frac{1}{4}$ sue $\frac{\Phi_{2}}{2}<0$

The conclusion in Property 3 is not straightforward. When optimal online and offline prices are realized in the SC under a specific RSR-RC, the marginal cost per unit should be the same with the marginal profit; the increase of RSR-RC improves retailers' used product recycling rates and generates more cost saving(s) in the SC, making the unit marginal contribution larger than the unit marginal cost. At the same time, the optimal online or offline price in the SC inevitably decreases until the marginal cost and marginal profit become equal again according to the Law of Diminishing Marginal Returns, which will boost market demand.

\subsubsection{The property analysis to optimal advertising investment}

Property 4. The relationship between optimal advertising investment and RSR-RC depends on advertising effect and is uncertain.

$\frac{d \mathrm{~b}_{0}^{*}}{d \Phi_{2}}=\frac{-k s \mu e^{\frac{1}{2} \Phi_{2}}}{8}\left(k^{2} A-1\right)^{-1}$

When $k^{2} A-1<0, \frac{d \mathrm{~b}_{0}^{*}}{d \Phi_{2}}>0$, the optimal advertising investment is a monotonically increasing function with respect to the RSR-RC, so the larger the RSR-RC, the larger the adverting investment.

When $k^{2} A-1 \geq 0, \frac{d b_{0}^{*}}{d \Phi_{2}}<0$, the optimal advertising investment is a monotonically decreasing function with respect to the RSR-RC, so the larger the RSR-RC, the smaller the adverting investment.

\subsubsection{The property analysis to optimal profit of the SC}

It can be learned from Theorem 3 that the optimal SC profit exists, shown in Formula (10). Take the derivatives of Formula (10) with respect to $\Phi_{2}$ :

$\frac{d \pi^{*}\left(\Phi_{2}\right)}{d \Phi_{2}}=\frac{1}{4} S \mu e^{\frac{1}{2} \Phi_{2}}\left(2(\beta-\delta) S \mu e^{\frac{1}{2} \Phi_{2}}+k \sqrt{b}+Q-2 c(\beta-\delta)\right)$

Then we can get:

Property 5. The relationship between optimal profit and RSR-RC is not certain. It depends on total market demand and RSR-RC.
Suppose $\mathrm{W}=\frac{k \sqrt{b}+Q-2 c(\beta-\delta)}{2(\beta-\delta) S \mu}$.

(1) if $\Phi_{2}>2 \ln W$ when $0<Q<2 c(\beta-\delta)-k \sqrt{b}$, then $\frac{d \pi\left(\Phi_{2}\right)}{d \Phi_{2}}>0$, and the optimal profit of the $\mathrm{SC}$ is a monotonically increasing function with respect to the RSR-RC; if $0<\Phi_{2}<2 \ln W$ then $\frac{d \pi\left(\Phi_{2}\right)}{d \Phi_{2}}<0$, and the optimal profit of the SC is a monotonically decreasing function with respect to the RSR-RC.

(2) $\frac{d \pi\left(\Phi_{2}\right)}{d \Phi_{2}}>0$ holds when $Q>2 c(\beta-\delta)-k \sqrt{b}$, and the optimal profit of the SC is a monotonically decreasing function with respect to the RSR-RC.

Property 6. The relationship between optimal profit and advertising investment is not certain and depends on advertising effect.

When advertising investment is the critical value, shown in Formula (9), the SC obtains its optimal profit, shown in Formula (10).

Then,

(1) When $k^{2} A-1<0$, the total profit of the SC is a concave function with respect to advertising investment on $[0,+\infty]$. The optimal advertising investment is $b_{0}^{*}$ and the optimal profit of the SC is $\pi^{c}\left(\sqrt{\mathrm{b}_{0}^{*}}\right)$.

(2) When $k^{2} A-1 \geq 0$, the total profit of the SC is a monotonically increasing function with respect to advertising investment on $[0,+\infty]$. The larger the advertising investment, the larger the SC profit.

It can be learned from Property 6 that there is a critical value of advertising affect $\sqrt{1 / A}$. When the influence factor of advertising investment to total market demand $k$ is smaller than the critical value, the advertising investment has an optimal level, $\sqrt{b_{0}^{*}}$, resulting in the SC reaching its profit. This means that the advertising effect makes SC profits increase with less advertising investment. On the other hand, when advertising investment exceeds $\sqrt{b_{0}^{*}}$, the SC profit decreases since returns on increased sale is not able to cover the advertising cost. When $k$ is larger than the critical value the advertising effect is sufficiently strong and the total profit of the SC is continuously increasing. Returns on increased sale will cover the advertising cost no matter how much is invested in advertising.

\subsection{Numerical analysis of centralized decision model with recycle rate change}

Suppose the values of parameters in the model are $Q=500$, $b=400, \mathrm{c}=10, s=3, \mu=0.8, \beta=8.5$ and $\delta=4.5$. In the previous analysis, advertising effect $k$ has a critical value, $\sqrt{1 / A}$, and the relationship between different variables are affected when $k$ is within different ranges. Therefore, if we suppose $k=4$ and $k^{2} A-1<0$, the preference is $\rho=0.4$ and the range of RSR-RC is $[0,1]$, with other parameters maintained in our analysis to verify the relationship between online and offline prices, optimal advertising investment, total SC profit and RSR-RC.

\subsubsection{Relationship between the optimal online/offline price and RSR-} $R C$

It can be known from Fig. 2 that the optimal online and offline prices are monotonically decreasing functions with respect to the 


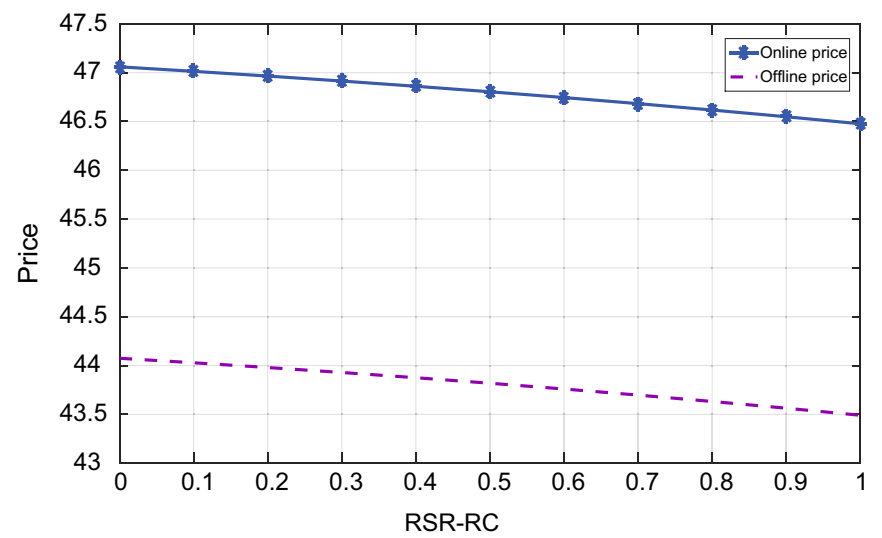

Fig. 2. Relationship between the optimal Online/Offline Price and RSR-RC.

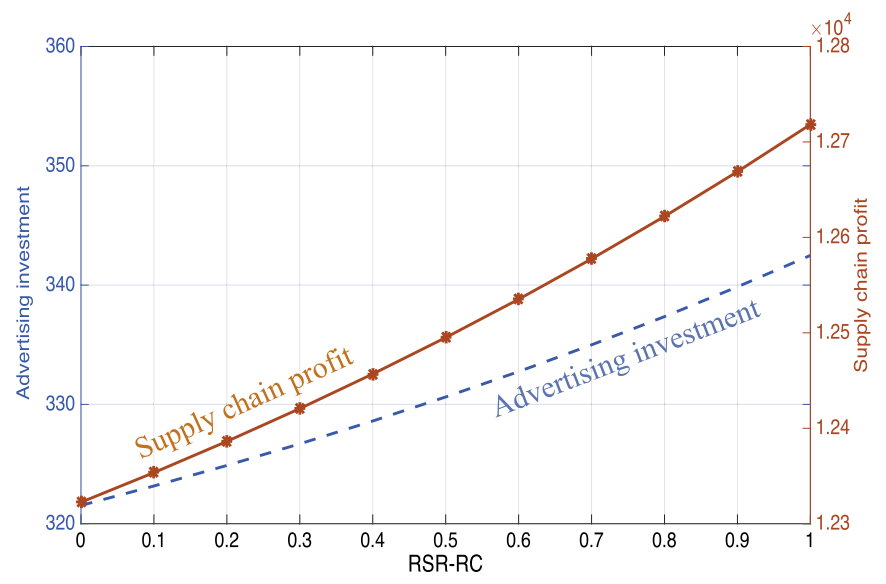

Fig. 3. Relationship between the optimal SC profit/optimal advertising investment and RSR-RC.

RSR-RC, which conforms to the conclusion in Property 3.

3.3.2. Relationship between the optimal SC profit/optimal advertising investment and RSR-RC

It can be known from Fig. 3 that when $k$ is small, that is $k^{2}$ $A-1<0$, then the optimal advertising investment is a monotonically increasing function with respect to the RSR-RC, which conforms to the conclusion in Property 4. When market demand is large and $k$ is small, then the optimal SC profit is a monotonically increasing function with respect to the RSR-RC, which conforms to the conclusion in Property 5. Different from the premise of fixed recycling rate of used products in previous research (QuariguasiFrota-Neto and Bloemhof, 2011; Debo et al., 2006), the recycling rate in this paper is affected by recycling channel input. Meanwhile, channel input is affected by revenue sharing of retailers in reverse SC. Thus, the SC profits are affected by production costs and sales price as well as RSR-RC. Furthermore, the larger the RSR$\mathrm{RC}$, the larger the adverting investment and SC profits. It solves the optimal pricing issues of $\mathrm{O} 2 \mathrm{O}$ dual-channel CLSC with cooperative advertisement, which can be considered as extension for former research.

\section{Channel conflict coordination model of cooperation adver- tising in decentralized CLSC}

\subsection{Decentralized decision model and solution of the model}

Under the circumstances of decentralized decision-making, suppose the manufacturer and retailer are parties in the Stackelberg game theory, with the manufacturer as the dominant party and the retailer as the following party. The manufacturer decides the allocation ratios $\Phi_{1}, \Phi_{2}$, the online and wholesale prices, and the advertising investment, then the retailer determines the offline price accordingly.

The profit function of the manufacturer:

$$
\begin{aligned}
\pi_{M}= & \left(\Phi_{1} P_{t}+w\right)\left(\rho(Q+k \sqrt{b})-\beta P_{t}+\delta P_{e}\right) \\
& +P_{e}\left((1-\rho)(Q+k \sqrt{b})-\beta P_{e}+\delta P_{t}\right) \\
& +\left(\left(1-\Phi_{2}\right) s \mu e^{\frac{1}{2} \Phi_{2}}-c\right)\left(Q+(\delta-\beta)\left(P_{t}+P_{e}\right)+k \sqrt{b}\right)-\alpha b
\end{aligned}
$$

The profit function of the retailer:

$$
\begin{aligned}
\pi_{R}= & \left(\left(1-\Phi_{1}\right) P_{t}-w\right)\left(\rho(Q+k \sqrt{b})-\beta P_{t}+\delta P_{e}\right) \\
& +\Phi_{2} S \mu e^{\frac{1}{2} \Phi_{2}}\left(Q+(\delta-\beta)\left(P_{t}+P_{e}\right)+k \sqrt{b}\right)-(1-\alpha) b
\end{aligned}
$$

Theorem 4. In the cooperative decision model of channel conflict coordination in decentralized CLSCS, the manufacturer's profit function is a strictly combined concave function with respect to $P_{e}$ and $w$, but not a combined concave function with respect to $P_{e}, w, \sqrt{b}, \Phi_{1}, \Phi_{2}$.

First of all, resolve the first derivative of $\pi_{R}$ with respect to $P_{t}$ with backward induction, the optimal offline price is resolved thus:

$$
\begin{aligned}
\mathrm{P}_{t}^{*}= & \frac{1}{2 \beta\left(1-\Phi_{1}\right)}\left[\delta\left(1-\Phi_{1}\right) P_{e}+\beta w+\rho(Q+k \sqrt{b})\left(1-\Phi_{1}\right)\right. \\
& \left.+\Phi_{2} S \mu e^{\frac{1}{2} \Phi_{2}}(\delta-\beta)\right]
\end{aligned}
$$

By substituting Eq. (13) into (11), the manufacturer's profit function is:

$$
\begin{aligned}
\pi_{M}^{\Delta}= & \left\{w+\frac{\Phi_{1}}{2 \beta\left(1-\Phi_{1}\right)}\left[\delta\left(1-\Phi_{1}\right) P_{e}+\beta w+\rho(Q+k \sqrt{b})\left(1-\Phi_{1}\right)\right.\right. \\
& \left.\left.+\Phi_{2} S \mu e^{\frac{1}{2} \Phi_{2}}(\delta-\beta)\right]\right\}\{\rho(Q+k \sqrt{b}) \\
& -\frac{1}{2\left(1-\Phi_{1}\right)}\left[\delta\left(1-\Phi_{1}\right) P_{e}+\beta w+\rho(Q+k \sqrt{b})\left(1-\Phi_{1}\right)\right. \\
& \left.\left.+\Phi_{2} S \mu e^{\frac{1}{2} \Phi_{2}}(\delta-\beta)\right]+\delta P_{e}\right\}+P_{e}\left\{(1-\rho)(Q+k \sqrt{b})-\beta P_{e}\right. \\
& +\frac{\delta}{2 \beta\left(1-\Phi_{1}\right)}\left[\delta\left(1-\Phi_{1}\right) P_{e}+\beta w+\rho(Q+k \sqrt{b})\left(1-\Phi_{1}\right)\right. \\
& \left.\left.+\Phi_{2} S \mu e^{\frac{1}{2} \Phi_{2}}(\delta-\beta)\right]\right\}+\left[\left(1-\Phi_{2}\right) S \mu e^{\frac{1}{2} \Phi_{2}}-c\right] \\
& \times\left[Q+k \sqrt{b}+(\delta-\beta)\left\{\frac { 1 } { 2 \beta ( 1 - \Phi _ { 1 } ) } \left[\delta\left(1-\Phi_{1}\right) P_{e}+\beta w\right.\right.\right. \\
& \left.\left.\left.+\rho(Q+k \sqrt{b})\left(1-\Phi_{1}\right)+\Phi_{2} S \mu e^{\frac{1}{2} \Phi_{2}}(\delta-\beta)\right]+P_{e}\right\}\right]-\alpha b
\end{aligned}
$$

For any given advertising investment $b$, and RSR-FC and RSR-RC $\Phi_{1}, \Phi_{2}$, the optimal online price and wholesale price of dual-channel SCs can be obtained with first-order optimality conditions. Furthermore, in the cooperative extension model of decentralized dual-channel CLSCs, the manufacturer's online price should be higher than the wholesale price. Otherwise retailers are able to buy products directly through the online channel, which makes the offline channel disappear, i.e. $P_{e}>w$.

The Lagrange multiplier $\lambda$ is then introduced to establish the 
Lagrange formula:

$$
\begin{aligned}
\pi_{M}^{\Delta}= & \left\{w+\frac{\Phi_{1}}{2 \beta\left(1-\Phi_{1}\right)}\left[\delta\left(1-\Phi_{1}\right) P_{e}+\beta w+\rho(Q+k \sqrt{b})\left(1-\Phi_{1}\right)\right.\right. \\
& \left.\left.+\Phi_{2} S \mu e^{\frac{1}{2} \Phi_{2}}(\delta-\beta)+s \mu e^{\frac{1}{2} \Phi_{2}}\left(1-\Phi_{2}\right)-c\right]\right\} \\
& \times\left\{\rho(Q+k \sqrt{b})-\frac{1}{2\left(1-\Phi_{1}\right)}\left[\delta\left(1-\Phi_{1}\right) P_{e}+\beta w\right.\right. \\
& \left.\left.+\rho(Q+k \sqrt{b})\left(1-\Phi_{1}\right)+\Phi_{2} S \mu e^{\frac{1}{2} \Phi_{2}}(\delta-\beta)\right]+\delta P_{e}\right\} \\
& +\left[P_{e}+s \mu e^{\frac{1}{2} \Phi_{2}}\left(1-\Phi_{2}\right)-c\right]\left\{(1-\rho)(Q+k \sqrt{b})-\beta P_{e}\right. \\
& +\frac{\delta}{2 \beta\left(1-\Phi_{1}\right)}\left[\delta\left(1-\Phi_{1}\right) P_{e}+\beta w+\rho(Q+k \sqrt{b})\left(1-\Phi_{1}\right)\right. \\
& \left.\left.+\Phi_{2} S \mu e^{\frac{1}{2} \Phi_{2}}(\delta-\beta)\right]\right\}-\alpha b+\lambda\left(P_{e}-w\right)
\end{aligned}
$$

We then resolve the first-order partial derivatives with respect to $P_{e}$ and $w$, and reduce them to 0 to obtain Kuhn-Tucker conditions for the manufacturer's optimization problem [Appendix B].

Since $P_{e}>w$, only the condition under $\lambda=0$ can be adopted. It can be obtained by resolving the manufacturer's optimization problem and Kuhn-Tucker conditions that:

$$
\begin{aligned}
P_{e}^{\Delta} & =\frac{\beta(1-\rho)+\delta \rho}{2\left(\beta^{2}-\delta^{2}\right)}(Q+k \sqrt{b})+\frac{c-\left(1-\Phi_{2}\right) s \mu e^{\frac{1}{2} \Phi_{2}}}{2} \\
& =\frac{N(Q+k \sqrt{b})+c-\left(1-\Phi_{2}\right) s \mu e^{\frac{1}{2} \Phi_{2}}}{2}
\end{aligned}
$$

$$
\begin{aligned}
w^{\Delta}= & \frac{\left(1-\Phi_{1}\right)}{2 \beta}\left(\left(\delta N+2 \rho-\frac{2 \rho}{2-\Phi_{1}}\right)(Q+k \sqrt{b})\right. \\
& \left.+\left(c-S \mu e^{\frac{1}{2} \Phi_{2}}\right)\left(\delta-\frac{2(\beta-\delta)}{2-\Phi_{1}}\right)-\delta \Phi_{2} S \mu e^{\frac{1}{2} \Phi_{2}}\right)+\Phi_{2} S \mu e^{\frac{1}{2} \Phi_{2}}
\end{aligned}
$$

$$
\begin{aligned}
P_{t}^{\Delta}= & \frac{1}{2 \beta}\left(\left(\delta N+2 \rho-\frac{\rho}{2-\Phi_{1}}\right)(Q+k \sqrt{b})\right. \\
& \left.+\left(c-s \mu e^{\frac{1}{2} \Phi_{2}}\right)\left(\delta+\frac{\beta-\delta}{2-\Phi_{1}}\right)+\delta \Phi_{2} S \mu e^{\frac{1}{2} \Phi_{2}}\right)
\end{aligned}
$$

Retailers and manufacturers are willing to implement a contract only when $\pi_{M}^{\Delta}+\pi_{R}^{\Delta}>\pi_{M}^{c^{*}}+\pi_{R}^{c^{*}}$. Meanwhile, substitute the expressions of $P_{e}^{\Delta}, w^{\Delta}, P_{t}^{\Delta}$ into (11) and (12) to resolve the profit function expressions of the manufacturer and the retailer. The profit functions of manufacturers' and retailers' are complicated, so we do not list them here. The relationship between RSR-FC and RSR-RC and manufacturer's profit, retailer's profit and SC profit under decentralized decision are analyzed with values in Part 4.3.

\subsection{Property analysis of the solutions of the decentralized decision model}

Property 7. The optimal offline price of retailer increases as the advertising investment increases; it decreases as the RSR-FC increases, but the relationship between it and the RSR-RC is not explicit.

Take the derivatives of Formula (17) with respect to $\sqrt{b}, \Phi_{1}, \Phi_{2}$ and it can be solved that: $\frac{d P_{t}^{\Delta}}{d \sqrt{b}}=\frac{k}{2 \beta}\left(\delta N+2 \rho-\frac{\rho}{2-\Phi_{1}}\right)>0$

$\frac{d P_{t}^{\Delta}}{d \Phi_{1}}=\frac{1}{2 \beta\left(2-\Phi_{1}\right)^{2}}\left((\beta-\delta)\left(c-s \mu e^{\frac{1}{2} \Phi_{2}}\right)-\rho(Q+k \sqrt{b})\right)<0$

The sign of $\frac{d P_{t}^{\Delta}}{d \Phi_{2}}=\frac{1}{4 \beta} S \mu e^{\frac{1}{2} \Phi_{2}}\left(\delta\left(\Phi_{2}+1\right)-\frac{\beta-\delta}{2-\Phi_{1}}\right)$ is not explicit, but correlated with the values of $\Phi_{1}, \Phi_{2}, \beta$ and $\delta$.

It can be seen from Property 7 that an increase in advertising investment can realize an increase in offline demand, so that retailers can price higher offline, which is easy to understand; while the negative correlation between the optimal offline price of retailers and RSR-FC is not as straightforward. We think the reason for this is that retailers' returns decrease following the rise in the RSR-FC and, as a result, they have to lower the price to accelerate sales and thus increase returns, as there is only the online sales channel in competition with retailers without considering price elasticity of product demand.

Property 8. Manufacturers' optimal online price rises as the advertising investment and RSR-RC increase, but it is not correlated with the RSR-FC.

By taking the derivatives of Eq. (15) with respect to $\sqrt{b}, \Phi_{1}, \Phi_{2}$, it can be solved that:

$\frac{d P_{e}^{\Delta}}{d \sqrt{b}}=\frac{N k}{2}>0$

$\frac{d P_{e}^{\Delta}}{d \Phi_{2}}=\frac{\left(1+\Phi_{2}\right) S \mu e^{\frac{1}{2} \Phi_{2}}}{4}>0$

$\frac{d P_{e}^{\Delta}}{d \Phi_{1}}=\frac{\mathrm{d} \frac{N(Q+k \sqrt{b})+c-\left(1-\Phi_{2}\right) s \mu e^{\frac{1}{2} \Phi_{2}}}{2}}{d \Phi_{1}}=0$

According to Property 8, a manufacturer's optimal online price rises as advertising investment increases, for manufacturers can set higher online prices when online demand increases along with a rise in advertising investment. A manufacturer's optimal online price is positively correlated with RSR-RC; the reason for this being that retailers are more active in the recycling of used products as RSR-RC increases. In other words, retailers are more dedicated in order to gain benefit from recycling activities when offline sales profit and recycling profit are also presence. This will weaken the effect of competition between offline and online sales channels, therefore, manufacturers can increase online prices to bring an increase in sales revenue without considering price elasticity of product demand.

Property 9. The online and offline prices under decentralized decisions are higher than those under centralized decisions [Appendix C].

By comparing $\mathrm{P}_{e}^{c^{*}}(\sqrt{b})$ and $\mathrm{P}_{e}^{\Delta}(\sqrt{b}), \mathrm{P}_{t}^{c^{*}}(\sqrt{b})$ and $\mathrm{P}_{t}^{\Delta}(\sqrt{b})$, it can be concluded that:

$$
\begin{aligned}
\mathrm{P}_{e}^{\Delta}(\sqrt{b})-\mathrm{P}_{e}^{c^{*}}(\sqrt{b})= & \frac{\Phi_{2} s \mu e^{\frac{1}{2} \Phi_{2}}}{2}>0 \\
\mathrm{P}_{t}^{\Delta}(\sqrt{b})-\mathrm{P}_{t}^{c^{*}}(\sqrt{b})= & \frac{1}{2 \beta}\left\{\delta \Phi_{2} s \mu e^{\frac{1}{2} \Phi_{2}}+\frac{1-\Phi_{1}}{2-\Phi_{1}}[\rho(Q+k \sqrt{b})\right. \\
& \left.-(\beta-\delta)\left(c-s \mu e^{\frac{1}{2} \Phi_{2}}\right)\right\}>0
\end{aligned}
$$

Property 9 indicates that both the manufacturer's price and the retailer's price under decentralized decisions are higher than those under centralized decisions, which means SC coordination is not realized under decentralized decisions, unlike under centralized decisions. In previous literatures (Cachon and Lariviere, 2005), 
although revenue-sharing contracts can eliminate double marginalization between manufacturers and retailers, and realize SC coordination compared with wholesale contracts, we think double marginalization still exists in revenue-sharing contracts under decentralized decisions. With the revenue allocation ratio determined, manufacturers and retailers seek to maximize their own profits through price decisions in the channel directly facing endconsumers.

\subsection{Value analysis of decentralized decisions}

For the purposes of this analysis, suppose the RSR-RC is $\Phi_{2}=0.4$, consumers' preference for the offline channel is $\rho=0$. 4, advertising investment is $b=400$ and other parameters remain unchanged.

\subsubsection{Relationship between optimal online/offline price, optimal} wholesale price and the RSR-FC

The relationship between the optimal online/offline price, the optimal wholesale price and the RSR-FC is shown in Fig. 4.

We can learn that the optimal online price is not correlative with the RSR-FC; the optimal offline price is a decreasing function with respect to RSR-FC. The optimal wholesale price is a convex function with respect to the RSR-FC, and has a larger change rate with respect to RSR-FC than optimal offline price with respect to RSR-FC.

\subsubsection{Relationship between the manufacturer's profit and the RSR- FC/RSR-RC}

As shown in Fig. 5, the manufacturer's profit is a monotonically decreasing function with respect to the RSR-RC when the RSR-FC remains unchanged. The manufacturer's profit is a monotonically increasing function with respect to the RSR-FC when the RSR-RC remains unchanged.

\subsubsection{Relationship between the retailer's profit and the RSR-FC/RSR-} $R C$

As shown in Fig. 6, the retailer's profit is a monotonically increasing function with respect to the RSR-RC when the RSR-FC remains unchanged. The retailer's profit is a monotonically decreasing function with respect to the RSR-FC when the RSR-RC remains unchanged.

\subsubsection{Relationship between the SC profit and the RSR-FC/RSR-RC}

As shown in Fig. 7, SC profit is a monotonically increasing function with respect to the RSR-RC when the RSR-FC remains unchanged. The SC profit is a monotonically increasing function with respect to the RSR-FC when the RSR-RC remains unchanged.

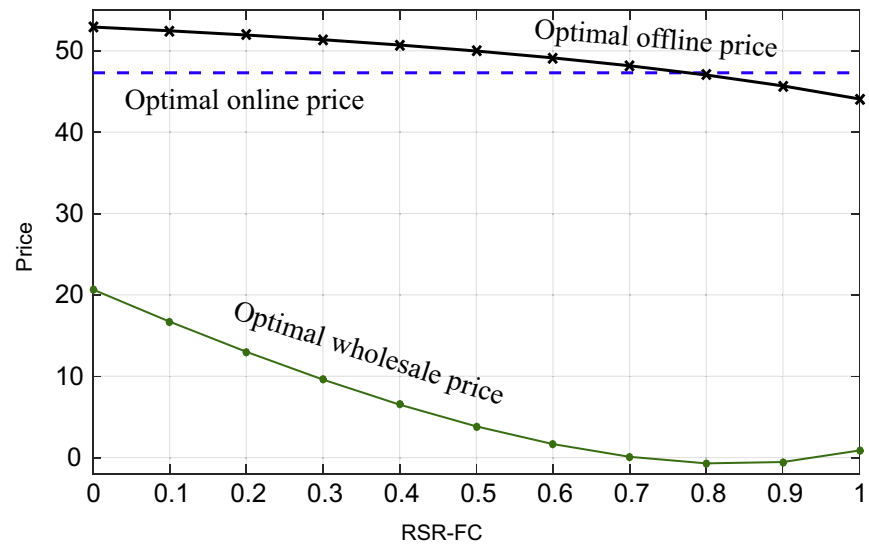

Fig. 4. The relationship between the optimal online/offline price, the optimal wholesale price and the RSR-FC.

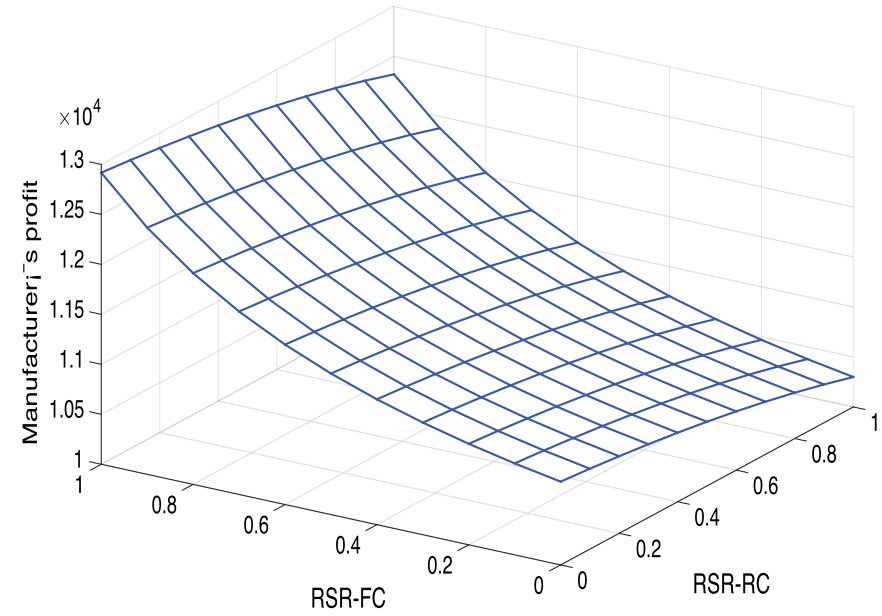

Fig. 5. Relationship between the manufacturer's profit and the RSR-FC/RSR-RC.

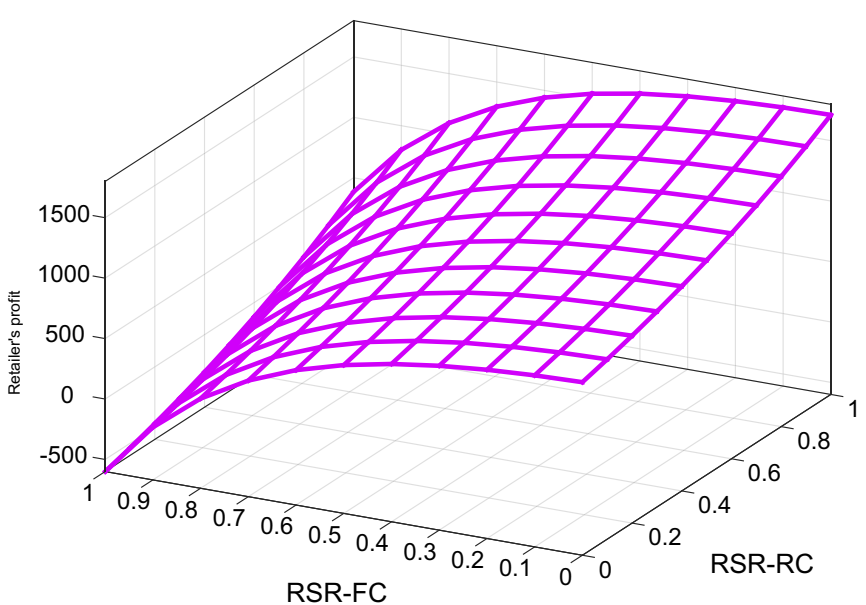

Fig. 6. Relationship between the retailer's profit and the RSR-FC/RSR-RC.

\section{Conclusion}

This paper constructs a dual-channel CLSC model consisting of single manufacturer/single retailer and researches the coordination of SC based on cooperative advertisement input and change of recycling rate for used products. It could be concluded that the optimized online and offline price will be increased with increasing in advertisement input. Under centralized decisions the optimal online/offline price and wholesale price are monotonically decreasing functions with respect to the RSR-RC. However, if advertisement stimulates demand growth, the optimized offline price would be reduced with increasing of RSRFC under decentralized decision while the optimized online price is not relevant to RSR-FC. In order to increase offline profit, the retailer will select offline price reduction sales strategy, but this strategy may not be the optimized price for the retailer. When the advertisement effect is small, the advertisement input level and profits of optimized $\mathrm{SC}$ are monotone increasing functions for RSR-RC. Thus, the setting for RSR-RC is critical for coordinating SC profit no matter under centralized or decentralized decision.

By comparison, both the optimal online and offline prices under decentralized decisions are higher than those under centralized decisions. Previous literatures say revenue-sharing contracts can eliminate double marginalization between manufacturers and retailers, and realize SC coordination compared with wholesale contracts, but under decentralized decisions, the optimal online/offline price strategy cannot be implemented in the same way as under 


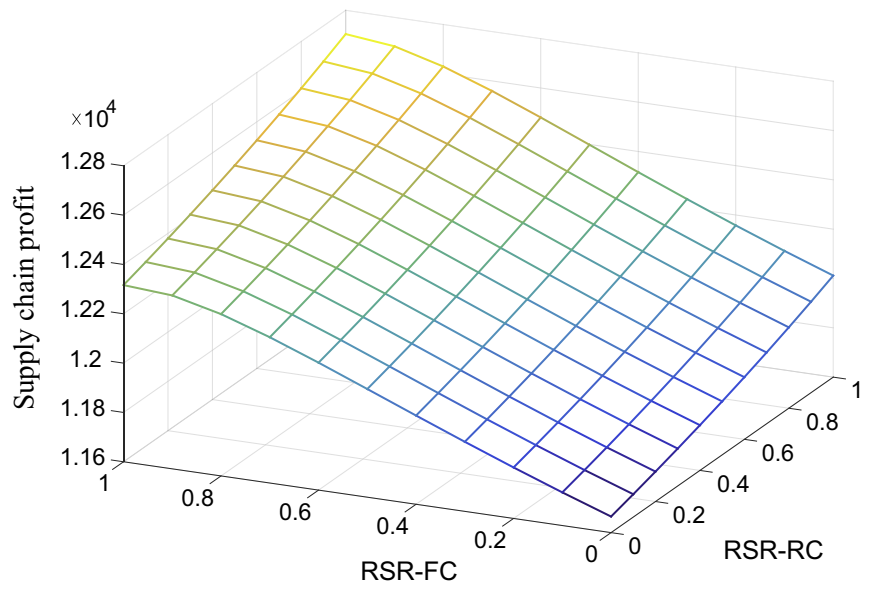

Fig. 7. Relationship between the SC profit and the RSR-FC/RSR-RC.

centralized decisions. Therefore, we think double marginalization still exists in revenue-sharing contracts under decentralized decisions. With the revenue allocation ratio determined, manufacturers and retailers seek to maximize their own profits through price decisions in the channel directly facing end-consumers.

The contribution of this paper include two parts: Firstly, it introduces advertisement cooperation into dual-channel CLSC so that the whole model can be more integral and closer to practical condition of economy. Under this condition, it is of practical significance to analyze the pricing strategy and advertisement investment strategy of enterprise in dual-channel CLSC; secondly, different from premise for fixed recycling rate of used products in previous research (QuariguasiFrota-Neto and Bloemhof, 2011; Debo et al., 2006), the recycling rate in this paper is affected by recycling channel input which is affected by revenue sharing of retailers in reverse SC. Thus, the recycling rate is not fixed in this paper and changes with the changing of sharing proportion. In this model, the SC profits are affected by production costs and sales price as well as RSR-RC. It solves the optimal pricing issues of $\mathrm{O} 2 \mathrm{O}$ dual-channel CLSC with cooperative advertisement, which can be considered as extension for former research.

This paper can provide some practical insights for managers. Recycling and remanufacturing is an important method for enterprises to reduce production cost and increase profit, especially for functional demand providing enterprises such as air conditioner enterprises which provides air control service for large building. Remanufactured equipment saves considerable cost with no impaction on demanded function. So it is worthy for managers to take account of how to make an efficient selling-recycling-remanufacturing strategy. According to our conclusion, the aim of advertising for manufacturer and distribution channel (or retailer) is to promote production selling as well as to establish the foundation of recycling in the future. To increase the enthusiasm for selling and recycling of retailer, manufacturer may adopt two-way revenue sharing contract to simulate retailer. When selling production, manufacturer sells production to retailer in a low wholesale price and shares profit of production selling of retailer. This is identical to traditional forward revenue sharing contract. When recycling, manufacturer shares saved cost by remanufacturing to retailer to stimulate the enthusiasm of retailer. This reverse revenue sharing is the main difference from traditional revenue sharing contract. Note that the share ratio of reverse revenue sharing affects advertising level and whole supply chain profit significantly. Besides, manufacturer should still maintain a well-established coordination relationship and make the whole supply chain and its members profit maximum by centralized decision making on online and offline price.

The future research is needed since there exists many uncertain factors that may affect remanufacturing efficiency in the practice. These uncertainties may further affect online and offline pricing strategy on dual-channel production and the design of revenue sharing contract parameters. For example, the quality of used product is not consistent. Under different quality level, the cost of remanufacturing is not the same. Under limited production resource, not all the used products will be used for remanufacturing. Manufacturer may filter out low quality used product in the practice. Besides, the amount of recycling and selling is independent in this paper. It is acceptable in certain condition but not always. In future work, the relationship between the amount of recycling and selling should be taken into consideration. Our model can be improved by making the quality level of used product endogenous variables or adding relationship between the amount of recycling and selling. In this way we can further discuss the coordination contract of closedloop supply chain and the practical importance on remanufacturing.

\section{Acknowledgment}

The work was supported by the National Natural Science Foundation of China (Grant nos. 71272015 and 71273091).

\section{Appendix A}

PROOF Take the second-order partial derivatives of Formula (6) with respect to $P_{t}, P_{e}, \sqrt{b}, \Phi_{2}$ and obtain Hessian Matrix.

$H=\left(\begin{array}{cccc}-2 \beta & 2 \delta & k & \frac{T}{2}(\delta-\beta) \\ 2 \delta & -2 \beta & k & \frac{T}{2}(\delta-\beta) \\ k & k & -2 & \frac{T}{2} k \\ (\delta-\beta) T & (\delta-\beta) T & k T & T B / 4\end{array}\right)$

where $T=s \lambda e^{0.5 \Phi_{2}}, B=Q+(\delta-\beta)\left(P_{t}+P_{e}\right)+k \sqrt{b}$

It can be solved that:

(1) $\partial^{2} \pi / \partial \sqrt{b}^{2}<0, \pi\left(P_{t}, P_{e}, \sqrt{b}, \Phi_{2}\right)$ is a strictly concave function with respect to $\sqrt{b}$.

(2) $\partial^{2} \pi / \partial P_{t}^{2}=-2 \beta<0, \partial^{2} \pi / \partial P_{t}^{2} * \partial^{2} \pi / \partial P_{e}^{2}-\partial^{2} \pi / \partial P_{e} \partial P_{t} * \partial^{2} \pi / \partial P_{t} \partial P_{e}$ $=4\left(\beta^{2}-\delta^{2}\right)>0$,

$\pi\left(P_{t}, P_{e}, \sqrt{b}, \Phi_{2}\right)$ is the strictly united concave function with respect to $P_{t}$ and $P_{e}$.

(3) $\partial^{2} \pi / \partial P_{e}^{2 *} \partial^{2} \pi / \partial P_{e}^{2}-\partial^{2} \pi / \partial \sqrt{b} \partial P_{e} * \partial^{2} \pi / \partial P_{e} \partial \sqrt{b}=4 \beta-k^{2}$, The relationship between $4 \beta-k^{2}$ and 0 is not explicit, then $\pi\left(P_{t}, P_{e}, \sqrt{b}, \Phi_{2}\right)$ is not the strictly united concave function with respect to $P_{e}$ and $\sqrt{b}$.

(4) $\partial^{2} \pi / \partial P_{t}^{2 *} \partial^{2} \pi / \partial \Phi_{2}{ }^{2}-\partial^{2} \pi / \partial \Phi_{2} \partial P_{t} * \partial^{2} \pi / \partial P_{t} \partial \Phi_{2}=\partial^{2} \pi / \partial P_{e}{ }^{2} * \partial^{2} \pi / \partial \Phi_{2}{ }^{2}$ $-\partial^{2} \pi / \partial \Phi_{2} \partial P_{e} * \partial^{2} \pi / \partial P_{e} \partial \Phi_{2}=-0.5\left[\beta T B+(\delta-\beta)^{2} T^{2}\right]<0, \pi\left(P_{t}\right.$, $\left.P_{e}, \sqrt{b}, \Phi_{2}\right)$

is not the strictly united concave function with respect to $P_{t}$ and $\Phi_{2}$, and also not the strictly united concave function with respect to $P_{e}$ and $\Phi_{2}$.

\section{Appendix B}

PROOF Introduce the Lagrange multiplier $\lambda$ to establish the Lagrange formula: 


$$
\begin{aligned}
\pi_{M}^{\Delta}=\{ & w+\frac{\Phi_{1}}{2 \beta\left(1-\Phi_{1}\right)}\left[\delta\left(1-\Phi_{1}\right) P_{e}+\beta w+\rho(Q+k \sqrt{b})\left(1-\Phi_{1}\right)\right. \\
& \left.\left.+\Phi_{2} S \mu e^{\frac{1}{2} \Phi_{2}}(\delta-\beta)+s \mu e^{\frac{1}{2} \Phi_{2}}\left(1-\Phi_{2}\right)-c\right]\right\}\{\rho(Q+k \sqrt{b}) \\
& -\frac{1}{2\left(1-\Phi_{1}\right)}\left[\delta\left(1-\Phi_{1}\right) P_{e}+\beta w+\rho(Q+k \sqrt{b})\left(1-\Phi_{1}\right)\right. \\
& \left.\left.+\Phi_{2} S \mu e^{\frac{1}{2} \Phi_{2}}(\delta-\beta)\right]+\delta P_{e}\right\}+\left[P_{e}+S \mu e^{\frac{1}{2} \Phi_{2}}\left(1-\Phi_{2}\right)-c\right] \\
& \times\left\{(1-\rho)(Q+k \sqrt{b})-\beta P_{e}+\frac{\delta}{2 \beta\left(1-\Phi_{1}\right)}\left[\delta\left(1-\Phi_{1}\right) P_{e}\right.\right. \\
& \left.\left.+\beta w+\rho(Q+k \sqrt{b})\left(1-\Phi_{1}\right)+\Phi_{2} S \mu e^{\frac{1}{2} \Phi_{2}}(\delta-\beta)\right]\right\}-\alpha b \\
& +\lambda\left(P_{e}-w\right)
\end{aligned}
$$

In resolving the first-order partial derivatives with respect to $P_{e}$ and $w$, and making them 0 we obtain Kuhn-Tucker conditions for manufacturer's optimization problem.

$$
\begin{aligned}
\frac{\partial L_{M}^{\Delta}}{\partial P_{e}}= & {\left[-2 \beta+\frac{\delta^{2}}{2 \beta}\left(2+\Phi_{1}\right)\right] P_{e}+\frac{\delta\left(2-\Phi_{1}\right)}{2\left(1-\Phi_{1}\right)} w } \\
& +\left[1-\rho+\frac{\delta \rho\left(1+\Phi_{1}\right)}{2 \beta}\right](Q+k \sqrt{b}) \\
& +\left[\frac{\delta(\delta-\beta)}{2 \beta\left(1-\Phi_{1}\right)}-\frac{\delta \beta+\delta^{2}-2 \beta^{2}}{2 \beta}\right] \Phi_{2} S \mu e^{\frac{1}{2} \Phi_{2}} \\
& +\frac{\delta \beta+\delta^{2}-2 \beta^{2}}{2 \beta}\left(s \mu e^{\frac{1}{2} \Phi_{2}}-c\right)+\lambda=0 \\
\frac{\partial L_{M}^{\Delta}}{\partial \mathrm{W}}= & \frac{\delta\left(2-\Phi_{1}\right)}{2\left(1-\Phi_{1}\right)} P_{e}-\frac{\beta\left(2-\Phi_{1}\right)}{2\left(1-\Phi_{1}\right)^{2}} w+\frac{\rho}{2}(Q+k \sqrt{b}) \\
& -\frac{\left(2-\Phi_{1}\right)(\delta-\beta)}{2\left(1-\Phi_{1}\right)^{2}} \Phi_{2} S \mu e^{\frac{1}{2} \Phi_{2}}+\frac{\delta-\beta}{2\left(1-\Phi_{1}\right)}\left(s \mu e^{\frac{1}{2} \Phi_{2}}-c\right)-\lambda=0 \\
& \lambda\left(P_{e}-w\right)=0
\end{aligned}
$$

Since $P_{e}>w$, only the condition under $\lambda=0$ can be adopted. It can be obtained by resolving the manufacturer's optimization problem and Kuhn-Tucker conditions:

$$
\begin{aligned}
P_{e}^{\Delta}= & \frac{[\beta(1-\rho)+\delta \rho](Q+k \sqrt{b})}{2\left(\beta^{2}-\delta^{2}\right)}+\frac{c-\left(1-\Phi_{2}\right) S \mu e^{\frac{1}{2} \Phi_{2}}}{2} \\
& =\frac{N(Q+k \sqrt{b})+c-\left(1-\Phi_{2}\right) S \mu e^{\frac{1}{2} \Phi_{2}}}{2} \\
& w^{\Delta}=\frac{\left(1-\Phi_{1}\right)}{2 \beta}\left(\left(\delta N+2 \rho-\frac{2 \rho}{2-\Phi_{1}}\right)(Q+k \sqrt{b})\right. \\
& \left.+\left(c-s \mu e^{\frac{1}{2} \Phi_{2}}\right)\left(\delta-\frac{2(\beta-\delta)}{2-\Phi_{1}}\right)-\delta \Phi_{2} S \mu e^{\frac{1}{2} \Phi_{2}}\right)+\Phi_{2} S \mu e^{\frac{1}{2} \Phi_{2}} \\
P_{t}^{\Delta}= & \frac{1}{2 \beta}\left(\left(\delta N+2 \rho-\frac{\rho}{2-\Phi_{1}}\right)(Q+k \sqrt{b})+\left(c-s \mu e^{\frac{1}{2} \Phi_{2}}\right)\right. \\
& \left.\left(\delta+\frac{\beta-\delta}{2-\Phi_{1}}\right)+\delta \Phi_{2} S \mu e^{\frac{1}{2} \Phi_{2}}\right)
\end{aligned}
$$

Retailers and manufacturers are willing to activity to implement contract only when $\pi_{M}^{\Delta}+\pi_{R}^{\Delta}>\pi_{M}^{c^{*}}+\pi_{R}^{c^{*}}$.

\section{Appendix C}

PROOF (1) Compare $P_{e}^{c^{*}}(\sqrt{b})$ and $P_{e}^{\Delta}(\sqrt{b})$ :

$$
\begin{aligned}
P_{e}^{\Delta}(\sqrt{b})-P_{e}^{c^{*}}(\sqrt{b})= & \frac{N(Q+k \sqrt{b})+c-\left(1-\Phi_{2}\right) s \mu e^{\frac{1}{2} \Phi_{2}}}{2} \\
& -\frac{N(Q+k \sqrt{b})+c-s \mu e^{\frac{1}{2} \Phi_{2}}}{2}=\frac{\Phi_{2} S \mu e^{\frac{1}{2} \Phi_{2}}}{2}>0
\end{aligned}
$$

(2) Compare $P_{t}^{c^{*}}(\sqrt{b})$ and $P_{t}^{\Delta}(\sqrt{b})$ :

$$
\begin{aligned}
P_{t}^{\Delta}(\sqrt{b})-P_{t}^{c^{*}}(\sqrt{b})= & \frac{1}{2 \beta}\left(\left(\delta N+2 \rho-\frac{\rho}{2-\Phi_{1}}\right)(Q+k \sqrt{b})\right. \\
& \left.+\left(c-s \mu e^{\frac{1}{2} \Phi_{2}}\right)\left(\delta+\frac{\beta-\delta}{2-\Phi_{1}}\right)+\delta \Phi_{2} S \mu e^{\frac{1}{2} \Phi_{2}}\right) \\
& -\frac{1}{2}\left(\frac{\beta \rho+\delta(1-\rho)}{\beta^{2}-\delta^{2}}(Q+k \sqrt{b})+c-s \mu e^{\frac{1}{2} \Phi_{2}}\right) \\
= & \frac{1}{2 \beta}\left\{\delta \Phi_{2} S \mu e^{\frac{1}{2} \Phi_{2}}+\frac{1-\Phi_{1}}{2-\Phi_{1}}[\rho(Q+k \sqrt{b})\right. \\
& \left.-(\beta-\delta)\left(c-s \mu e^{\frac{1}{2} \Phi_{2}}\right)\right\}
\end{aligned}
$$

Because $c-s \mu e^{\frac{1}{2} \Phi_{2}}<P_{e}$, then can get

$$
\begin{array}{r}
\rho(Q+k \sqrt{b})-(\beta-\delta)\left(c-s \mu e^{\frac{1}{2} \Phi_{2}}\right)>\rho(Q+k \sqrt{b})-(\beta-\delta) P_{e} \\
>\rho(Q+k \sqrt{b})-\beta P_{t}+\delta P_{e}=D_{t} \geq 0
\end{array}
$$

so $P_{t}^{\Delta}(\sqrt{b})-P_{t}^{c^{*}}(\sqrt{b})>0$

\section{References}

Altug, M.S., 2016. Supply chain contracting for vertically differentiated products. Int J. Prod. Econ. 171, 34-45.

Cachon, M.A., Lariviere, 2005. Supply chain coordination with revenue-sharing contracts: strengths and limitations. Manag. Sci. 51 (1), 30-44.

Dan, B., Xu, G., Liu, C., 2012. Pricing policies in a dual channel supply chain with retail services. Int. J. Prod. Econ. 139, 312-320.

Debo, L.G., Toktay, L.B., Wassenhove, L.N.V., 2006. Joint life-cycle dynamics of new and remanufactured products. Prod. Oper. Manag. 15 (4), 498-513.

Gallego, G., Hu, M., 2014. Dynamic pricing of perishable assets under competition. Manag. Sci. 60 (5), 1241-1259.

Horsky, D., Simon, L.S., 1983. Advertising and the diffusion of new products. Mark Sci. 2 (1), 1-17.

Hua, G., Wang, S., Cheng, T.C.E., 2010. Price and lead time decisions in dual-channel supply chains. Eur. J. Oper. Res. 205, 113-126.

Jing, C., Bell, P.C., 2012. Implementing market segmentation using full-refund and no-refund customer returns policies in a dual-channel supply chain structure. Prod. Econ. 136, 56-66.

Krishnan, H., Winter, R.A., 2011. On the role of revenue-sharing contracts in supply chains. Oper. Res. Lett. 39 (1), 28-31.

Niu, R.H., Zhao, X., Castillo, I., Joro, T., 2012. Pricing and inventory strategies for a two-stage dual-channel supply chain. Asia Pac. J. Oper. Res. 20, 1-38.

Park, S.Y., Keh, H.T., 2003. Modeling hybrid distribution channels: a game-theoretic analysis. J. Retail. Consum. Serv. 10 (3), 155-167.

Peng, J., Lin, J., Lin, Z., Wu, X.Y., 2015. Competing and coordination strategies for dual-channel supply chain with demand disruption. J. TongJi Univ. (Nat. Sci.) 43 (1), 146-152.

Pietro, D.G., 2014. Environmental collaboration in a closed-loop supply chain with a reverse revenue sharing contract. Ann. Oper. Res. 220, 135-157.

Quariguasi-Frota-Neto, J., Bloemhof, J., 2011. An analysis of the eco-efficiency of remanufactured personal computers and mobile phones. Prod. Oper. Manag. 21 (1), 101-114.

Savaskan, R.C., Bhattacharya, S.V., Wassenhove, L.N., 2004. Closed-loop supply chain models with product remanufacturing. Manag. Sci. 50 (2), 239-252.

Szmerekovsky, J.G., Zhang, J., 2009. Pricing and two-tier advertising with one manufacturer and one retailer. Eur. J. Oper. Res. 192, 904-917.

Wang, Y.Z., Jiang, L.S., Zuo, J., 2004. Channel performance under consignment contract with revenue sharing. Manag. Sci. 50 (1), 34-47.

Wei, Y., Choi, T.M., 2012. Mean-variance analysis of supply chains under wholesale pricing and profit sharing schemes. Eur. J. Oper. Res. 204 (4), 255-262.

Xie, J.X., Wei, J.C., 2009. Coordinating advertising and pricing in a manufacturerretailer channel. Eur. J. Oper. Res. 197, 785-791. 
Xing, K., Belusko, M., Luong, L., 2007. An evaluation model of product upgradeability for remanufacture. Int. J. Adv. Manuf. Technol. 35, 1-14.

Xu, G.Y., Dan, B., Zhang, X.M., Liu, C., 2014. Coordinating a dual-channel supply chain with risk-averse under a two-way revenue sharing contract. Prod. Econ. 147, 171-179.

Yan, R.L., Pei, G., 2011. Information asymmetry, pricing strategy and firm's performance in the retailer multi-channel manufacturer supply chain. J. Bus. Res. 64, $377-384$
Yi, Y.Y., Yuan, J., 2012. Pricing coordination of closed-loop supply chain in channel conflicts environment. J. Manag. Sci. China 15 (1), 54-65.

Yi, Y.Y., Xiao, L.J., 2012. Closed-loop supply chain model with advertising effect. Manag. Rev. 24 (11), 44-50.

Yue, J.F., Austin, J., Wang, M.C., Huang, Z.M., 2006. Coordination of cooperative advertising in a two level supply chain when manufacturer offers discount. Eur. J. Oper. Res. 168 (1), 65-85. 